\title{
Erratum zu: Kundendialog online und offline
}

\section{Erratum zu: R. T. Kreutzer, Kundendialog online und offline, https://doi.org/10.1007/978-3-658-30119-4}

Ein technischer Fehler im Produktionsablauf hat dazu geführt, dass das Buch zunächst mit 2020 als Copyright Jahr veröffentlicht wurde. Das Copyright Jahr ist 2021. Dies wurde nachträglich korrigiert.

Die aktualisierte Version des Buches finden Sie unter:

https://doi.org/10.1007/978-3-658-30119-4

(C) Springer Fachmedien Wiesbaden GmbH, ein Teil von Springer Nature 2021, 